\title{
El collage: Herramienta conceptual y compositiva del diseño arquitectónico de Richard Meier
}

\section{Collage: A conceptual and compositive tool of architectural design by Richard Meier}

\author{
DOI: 10.17981/mod.arq.cuc.24.1.2020.02
}

Artículo. Fecha de Recepción: 29/11/2019. Fecha de Aceptación: 10/12/2019.

\author{
Alberto Gutiérrez Lacombe \\ Universidad de la Costa (Colombia) \\ algulac@gmail.com
}

Para citar este artículo:

Gutiérrez, A. (2020). El collage: herramienta conceptual y compositiva del diseño arquitectónico de Richard Meier, MODULO ARQUITECTURA CUC, no. 24, pp. 27-48, 2020. DOI: http://doi.org/10.17981/mod.arq.cuc.24.1.2020.02.

\section{Resumen}

El collage es una técnica común en el arte moderno y contemporáneo, incluso en la creación de cine. El collage combina motivos pictóricos y fragmentos de origines desconectados dentro de una entidad sintética que otorga nuevos roles a esas partes. En el diseño arquitectónico esta técnica genera nuevas narrativas, diálogos, y yuxtaposiciones que ayudan a la capacidad de imaginar el espacio. El proceso de creación de collages utilizado por el arquitecto Richard Meier es de gran importancia en la concepción general y diseño arquitectónico de todos sus proyectos. Cada collage cuenta una historia mediante unos principios organizativos, un manejo del espacio basado en figuras geométricas, retículas, proporciones que deben ser precisamente estudiadas y calculadas. La maravillosa estética, forma y organización espacial de los proyectos de Meier radican en la abstracción de una idea en una serie de collages. El recorrido por el análisis de los collages de Richard Meier, nos permite concluir que, en el proceso de creación de Meier, el collage, existe como gesto inicial arquitectónico; no existe improvisación en las ideas que lo generan y no es solo un elemento primario de comunicación sino de creación.

Palabras clave: Collage; Diseño; Richard Meier; Creatividad; Proceso

\section{Abstract}

Collage is a common technique in modern and contemporary art, even in the creation of cinema. The collage combines pictorial motifs and fragments of disconnected origins within a synthetic entity that gives new roles to those parts. In architectural design this technique generates new narratives, dialogues, and juxtapositions that help the ability to imagine space. The process of creating collages used by the architect Richard Meier is of great importance in the general conception and architectural design of all his projects. Each collage tells a story through organizational principles, a management of space based on geometric figures, grids, proportions that must be precisely studied and calculated. The wonderful aesthetics, form and spatial organization of Meier's projects lie in the abstraction of an idea in a series of collages. The journey through the analysis of the collages by Richard Meier, allows us to conclude that, in the process of creating Meier, collage, exists as an initial architectural gesture; There is no improvisation in the ideas that generate it and it is not only a primary element of communication but also of creation.

Keywords: Collage; design; process; creativity; Richard Meier 


\section{INTRODUCCIÓN}

El dibujo es un excelente, o quizá, el principal medio de expresión usado por los arquitectos para transmitir un mensaje. Como bien lo señala Salgado, Raposo \& Butragueño (2017), a inicios de la segunda mitad del siglo XX, el dibujo en arquitectura estaba asociado a una notación codificada más cercana a la representación constructiva de la arquitectura que a su comunicación, sin embargo, a partir de los años sesenta, el dibujo arquitectónico fue adoptando un carácter más comunicativo hasta el punto de llegar a convertirse en un valioso instrumento de crítica al servicio de la arquitectura (Salgado, Raposo \& Butragueño, 2017).

Revisando la historia del término "diseño", se encontró, por una parte, lo que describe Bonsiepe como una popularización, algo muy de la cultura pop y que se describe como extensión horizontal de un concepto, y en el otro lado una gran contradicción el hecho del que comentó el crítico de arquitectura Witold Rybczynski sobre ese fenómeno, describiendo los ejemplos en los que definía, ya hace un buen tiempo, lo que era un diseñador. El caso de Eliot Noyes, quien era el responsable de diseñar la máquina de escribir Selectric para la IBM en la década de 1960, o Henry Dreyfuss, cuyos clientes incluyen Lockheed Aircraft y la Compañía de teléfonos Bell o el diseñador Dieter Rams, que crearon una gama de austeros, pero muy prácticos, productos para la empresa alemana Braun. Sin embargo, hoy en día, como diseñador se trae a colación a Ralph Lauren o Giorgio Armani, es decir, un diseñador de moda. Mientras que los diseñadores de moda usualmente comienzan como modistas; ellos, o al menos sus nombres, a menudo están asociados con una amplia variedad de productos de consumo, incluyendo cosméticos, perfumes, maletas, muebles para el hogar e incluso artículos para el hogar pintar. Como resultado, el "diseño" se identifica popularmente con el embalaje: La carcasa de un monitor de computadora, el barril de un bolígrafo y un marco para gafas (Bonsiepe, 2006). Y por este motivo en el imaginario general y popular de la población se olvida como el proceso de diseño no es algo mecanizado ni es solo un método para envolver productos.

Generalmente el proceso de diseño arquitectónico empieza de una manera inconsciente o por algún evento o experiencia que despierte interés y contribuya a la imaginación dando acción a una respuesta creativa (Bielefed, 2013), permitiendo la generación de distintas ideas, opciones y parámetros que se van decantando a medida que el proceso va madurando. El proceso de diseño arquitectónico es complejo y necesita de métodos o herramientas que logran organizar todas esas ideas, opciones y parámetros necesarios. Tales como la lluvia de ideas, el método de galerías, el método scamper, el cual es una técnica creativa que funciona como una lista de chequeo. Tiene como objetivo encontrar nuevas perspectivas y cuestionar ideas preconcebidas (Bielefed, 2013). Otros métodos son los mapas mentales y la utilización o interpretación de técnicas artísticas. Con el movimiento moderno, los arquitectos de la época optan por utilizar un mecanismo de composición formal comúnmente presente en la 
pintura y el arte plástico como lo era el collage. La técnica de ensamblar formas de distintas fuentes construir o crear otras es una característica intrínseca en la concepción de proyectos en la arquitectura moderna y en cierto punto va en contra o en oposición, en términos de la composición, a la importancia generada en la arquitectura contemporánea, la cual reformula el concepto de los elementos constitutivos por encima de sus relaciones en términos del diseño (Aschner, 2009). Un ejemplo claro es la utilización del collage que para Mies van der Rohe, significa un importante avance en la representación bidimensional de su idea del espacio (Spaeth, 1985), llevandolo y le permitiéndolo pensar y asumir de una forma diferente las condiciones de percepción de las obras desde distintos puntos de vista, organizaciones diversas o de una manera secuencial (Layuno, 2016). Mies van der Rohe toma el collage como herramienta para la generación de trabajos teóricos, tales como las casas patios en los años 30 dentro de su trabajo de docente en la Bauhaus. Luego, ya en los Estados Unidos de Norteamérica, continúa produciendo collages de manera experimental que le sirven, entre los años 1937 y 1954, como fundamento en proyectos como la casa Resor entre 1937 y 1943, el Museo para una ciudad pequeña entre 1940 y 1943, la Sala de conciertos entre 1941 y 1942 y Centro de congresos trabajado entre 1953 y 1954, y también funcionan como elementos de exploración e investigación de nuevas formas de pensar, de interpretar el espacio de manera más abstracta (Vallespin, Cervero, \& Cabodevila, 2017).
Mies solo es un ejemplo de arquitectos que utilizaron el collage como herramienta compositiva y como elemento de abstracción espacial. En general, muchos arquitectos aprecian o distinguen los elementos visuales y los principios organizativos del espacio como una solo unidad, como un gran todo, que está determinado por todo el conjunto y no por sus partes individuales (De Piccoli, 2015), tal y como se entiende un collage. $\mathrm{Y}$ es precisamente ese entendimiento de unidad lo que permite que una obra de arquitectura sea completamente perceptible.

Las técnicas artísticas como el collage y el montaje también influyeron en los trabajos conceptuales y en las obras de algunos arquitectos, tales como Bernard Tchumi y Rem Koolhaas, quienes hicieron propuestas acerca de cómo debe hacerse arquitectura basado no en los principios clásicos de ordenamiento espacial y otros normalmente usados como la continuidad y la articulación, sino en el choque entre eventos o acontecimientos (Prada, 2004).

\section{Entender el collage como herramienta de practica compositiva}

En el instante que se entiende el collage como una herramienta de composición arquitectónica se entiende también la importancia de la imagen en la modernidad, y se convierte en un proceso viable y fundamental para los arquitectos (De Molina, 2014). Rudolph Arnheim es una de las referencias más importantes del concepto "pensamiento visual". Arnheim (2001) describe que "percibir y pensar son actos que se encuentran 
indivisiblemente entremezclados", reconociendo así la existencia de otros tipos de pensamiento, algunos como consecuencia del acto perceptivo en el cual se incluyen las imágenes visuales que se constituyen en una forma de conocimiento humano. De esta manera, las imágenes permiten la transferencia del mundo de las ideas al mundo material. Así como lo expresa Brea citado por Castellanos y Rodríguez (2016), las imágenes constituyen regímenes escópicos entendidos como el conjunto de factores de índole físico y social que determinan los modos de ver de una época y un determinado contexto humano. De este modo, el pensamiento visual es superior a un sistema de representación, basado en imágenes, este es más un discurso propio que aporta al conocimiento. En palabras de Moxey (2009) implica ir de la concepción de representación al estatus de presentación, una entrada seminal para los estudios visuales, los cuales como campo 'indisciplinar' responden al reto que implica pensar la visualidad y los procesos de producción, circulación y consumo de imágenes en el contexto contemporáneo (Castellanos \& Rodriguez, 2016).

Según Meier esto es muy claro. Meier, generalmente va conceptualizando, dibujando y haciendo composiciones tipo collage en cuadernos de notas durante su tiempo libre incluso durante los viajes intercontinentales, utilizando materiales como periódicos, revistas y otros elementos pictóricos (Nesbitt, 1990). Todos estos ejercicios prácticos y artísticos llevan Meier a lograr una abstracción geométrica consciente o inconsciente que se ve reflejada en una configuración recurrente de un rectángulo posicionado de forma diagonal o girado de su base que contrasta con las curvas del papel rasgado y que en cierto modo asemejan algunos elementos arquitectónicos en sus edificios (Nesbitt, 1990). Tal es el caso del Museo de Arte Moderno de Barcelona-MACBA, en el cual una fachada completamente rectilínea se rompe con un elemento volumétrico de forma curva y libre.

Para Meier el collage se convirtió en un método cuyo fin es alcanzar la correcta composición en dos dimensiones y al mismo tiempo una herramienta creativa y compositiva que es altamente gratificante, ya que la mayoría de las veces, el proceso consiste el colocar algo, una imagen, un color o un recorte de papel y la composición queda lista y puede ser admirada inmediatamente. A diferencia de la Arquitectura, la cual es un proceso largo que puede durar años a partir del diseño hasta su construcción y luego su correcta ocupación (Shields, 2014).

Se puede entender que la racionalidad de los diseños de Meier esta fundamentada en su forma de pensar y de abstraerse, que va de la mano de la forma de hacer collages (Meier y Logan, 2016). Pensar y analizar todas las alternativas posibles de la composición hasta estar completamente satisfecho, pesos y puntos focales, direccionamientos y una organización fundamentada en los espacios de circulación permitiendo una claridad constante. Al comprender que el proceso de hacer collages es una herramienta importante para lograr buenas acciones compositivas tanto en dos dimensiones como en tres dimensiones. Meier usa y materializa el sentido común como punto alto 
en sus diseños y compara la organización espacial con el proceso creativo de hacer collages, advirtiendo que es un ejercicio de agilidad mental, de alto raciocinio y de práctica compositiva (Cabas, 2012). De igual manera Meier también utiliza la maqueta como una herramienta importante del proceso de diseño, organizando ideas conceptuales y estéticas, así como de la forma arquitectónica, de esta manera entiende todo como un gran proceso creativo, la utilización de la abstracción logrado con los collages junto a la plástica de las maquetas bajo unos principios arquitectónicos preconcebidos y otros dados por las características del proyecto (Cabas, 2017) le permiten generar una gran gama de ideas y organizaciones muy definidas. Es un hecho que el lenguaje de Meier hace énfasis en lo modular, el orden geométrico y la medida exacta, lo que se aprecia claramente en el revestimiento diseñado modularmente, la estructura y la organización general de los espacios en sus edificios y que Meier logra explicar en los diagramas interpretativos que hace en los libros que ha publicado. Aunque en las primeras casas, debido a que no se hicieron esos diagramas explicativos, no se sabe si Meier trabajó con esa regularidad geométrica y de proporción desde sus inicios o no (Dahabreh, 2014) pero sí se sabe que Meier experimentó con collages desde muy temprano en su carrera. Ya en 1959 luego de una período de transición en un pequeño estudio (Shields, 2014). Algo que se ve muy marcado en otros aspectos del lenguaje de Meier, que son igualmente importantes desde el punto de vista de las cualidades perceptivas y el juicio estético, y es que el ordenamiento geométrico permite que el ordenamiento del espacio abarque la composición, la estructura y la construcción (Dahabreh, 2014).

Al comprender que la técnica del collage funciona como herramienta de composición arquitectónica se logra una gran capacidad de abstracción, en el caso de la casa Douglas, luego del análisis realizado por Saleem Dahabreh; este mismo concluyó que la forma de esta casa en específico no solo depende de la relación entre el programa arquitectónico y el lenguaje formal que maneja Meier, sino que también está influenciada por elementos abstractos como la inversión o el giro los espacios. Este se hace notorio no solo en lo espacial sino en la materia física de la casa, la cual Meier manipula ingeniosamente para lograr resultados simples pero muy interesantes. (Dahabreh, 2014). Continua Dahabreh explicando como aunque el diseño luzca aparentemente simple y su organización espacial sea altamente rígida, disciplinada y regulada por la proporción aurea y un sistema regulado creado por el mismo arquitecto, la casa de Douglas en particular y los diseños de Meier en general, así como su interpretación de formal y la estética, no provienen de la complejidad de las formas mismas, sino de un acto creativo y complejo de la aplicación de la geometría superpuesta. Por esta razón, la completa integridad estética de formas simples que utiliza, como lo hizo en la casa Douglas, no nace ni es resultado de únicamente de los materiales, ni de las relaciones entre las distintas formas, sino que está fundamentada en la superposición compleja de principios geométricos y proporcionales así como en conceptos y te- 
mas abstractos de la forma material manifestada (Dahabreh, 2014).

Así que la práctica constante de hacer collages ha permitido a Richard Meier lograr una gran capacidad de abstracción geométrica y estética. Y entender que la técnica del collage no solo como técnica de representación sino de composición o hasta podría decirse de descomposición puede generar relaciones espaciales y arquitectónicas especiales y únicas. La conjugación en distintas cantidades de tramas, colores y piezas diferentes pueden plasmar distintas acercamientos o interpretaciones abstractas. Es el caso del arquitecto Guillermo Jullian, el cual utiliza esos métodos en todo su proceso creativo. Mediante colores y pequeños trozos de papel recortado que sirven de medida y proporción de sus proyectos (Bianchi y Perez, 2008). De igual manera en sus croquis aparecen distintas intensidades de colores, recortes y texturas que le van dando idea o forma a lo que tiene en su cabeza. Entonces si el collage se toma como herramienta compositiva del diseño arquitectónico se puede optar por distintas formas de usarlo. Teniendo en cuenta el color, que puede aparecer como línea o como mancha y estar asociado a un problema espacial de limites o de superficies o simplemente a usos del programa arquitectónico. Para Bianchi y Pérez (2008), el color funciona como un código para el arquitecto Guillermo Jullian, clasificando la vocación del espacio, así como la forma de construirlo. De esta manera Guillermo Jullian usa el color como elemento de explicación de la construcción de la obra y no para entender el vacío (Bianchi y Perez, 2008).
Una imagen, collage, diagrama, dibujo y cualquier obra de arte gráfica puede llegar a convertirse en una herramienta compositiva del diseño. Puede generar pensamientos nuevos, nuevas perspectivas conceptuales y generarle al diseñador una capacidad mayor para enfocar su atención (Der Mass, 2011). El diagrama es un elemento visual poderoso y cuando el arquitecto lo adopta como herramienta de diseño, le genera gran flexibilidad y sigue siendo abierto a la interpretación. El arquitecto es el que decide como usar ese instrumento y como es el aspecto de esa herramienta y en qué momento la puede utilizar e incorporarla a su proceso. Cualquier imagen, cualquier elemento gráfico, puede ser un diagrama (Der Mass, 2011). Esto incluye la técnica artística del collage, el cual se define como una imagen en la cual varios objetos o materiales; por ejemplo papel, tela o fotografías, están pegadas o colocadas juntas sobre una superficie mayor (Cambridge University Press, 2018).

\section{Proceso creativo y conceptual de} los collages de Richard Meier

Hacer collages para Meier es un ritual personal, practicar, crear, y en cierto modo dejar la monotonía de los viajes. Los materiales son fragmentos de revistas, tiquetes, postcards, fotografías que va recolectando para utilizarlos en algún momento y los incorpora en sus composiciones sin algún sentido o significado evidente. Colecciona esos elementos basado en sus colores, texturas, tipo de letra sin importar el sentido semántico. ¡Sus collages solo son collages! Son composiciones meramente estéticas, son intuitivas y casuales, pero en los últimos 
tiempos, el mismo Meier ha afirmado que intencionalmente ha buscado más relación y articulación entre los fragmentos y el lugar donde los recolecta (Shields, 2014).

El mismo Meier, comenta como comenzó a hacer collages en el año de 1959 y todavía sigue haciéndolo, también recalca que le fascina realizarlos. Para Meier, hacer collages, es un ejercicio intuitivo que le ayuda a mantener la agilidad mental y entrena al ojo del que los realiza para lograr mejores composiciones (Meier y Logan, 2016). Sigue explicando, como en varios aspectos, el hacer collages, tiene gran relación con la organización de los componentes del programa de necesidades de un edificio. El proceso de hacer collages puede empezar en cualquier lugar, generalmente Meier los realiza durante largos viajes en avión para ejercitar la mente y para pasar el rato, y lo que hace es usar las imágenes y los materiales que encuentra en el mismo vuelo, e incluso otros que lleva guardados en sus pertenencias. Artistas como Picasso y Braque, con su concepción cubista, o Malevich y Rodchenko con su estilo constructivista y las teorías neoclasicistas de Mondrian, Stella y Diebenhorn han influenciado en la concepción artística y arquitectónica de Meier, así como el manejo de las proporciones sencillas y la utilización sutil de los colores de Rohtko han permitido en Richard Meier una nueva visión intuitiva de hacer arquitectura o de hacer edificios elegantes como el mismo Meier expresa. El entendimiento y la interpretación de un programa de necesidades arquitectónico de un proyecto trae consigo un esfuerzo intuitivo de creación de orden, significados de configuraciones espaciales especificas y el equi- librio de distintos y múltiples elementos de la composición y en las que se hace énfasis en la línea, la textura, la forma y los espacios intermedios (Meier y Logan, 2016). Y en esto, la práctica constante de hacer collages le ha facilitado las cosas. Su proceso creativo para la realización de collages se establece en un formato cuadrado de 10x10 pulgadas, pero sin limitarse a la geometría direccional de ese modulo. Intencionalmente obvia las temáticas y tiende a presentar un favoritismo hacia la yuxtaposición de colores. Meier tiene muy claro que hacer collages es una técnica invaluable para mejorar la abstracción, también tiene claro que generalmente solo se ejecuta en dos dimensiones mientras que la arquitectura se realiza en tres dimensiones. Todo tiene que estar relacionado con el sentido del orden. En un edificio se organizan espacios de tres dimensiones y la se relacionan entre sí, al hacer collages también se piensa espacialmente, pero en sentido de dos dimensiones (Shields, 2014).

El proceso creativo de Meier, tanto para el collages como para la arquitectura, requiere de un alto grado de abstracción geométrica, organización y fragmentación, así como un sentido claro de la estructura. Siempre existe el concepto de fragmentación al momento de hacer los collages, generalmente emplea un orden rectilíneo, pero en algunos casos se relaciona con un elemento curvo, y la estructura en sus collages viene dada por los materiales que utiliza o tiene a disposición. En el caso de sus edificios la estructura viene dada por grillas o cuadriculas bien definidas en las cuales también logra apreciarse el concepto de fragmentación (Nesbitt, 1990). 
Organización espacial de las

obras de Meier y sus collages

Los edificios diseñados por Richard Meier está altamente influenciados por Le Corbusier, y po sus conceptos planteados como los cinco punto para una nueva arquitectura. De igual manera la utilización de una retícula en el proceso de diseño, que para Le Corbusier era más un elemento de organización estructural y no metodológico como es utilizada por Meier, quien interpreta la retícula como una herramienta de carácter proyectual. Esta herramienta proyectual, podría considerarse un sistema reticular, se ha desarrollado en tre variables distintas, como lo son, la retícula sobre curvas, la retícula ortogonal y las retículas yuxtapuestas con giros (Ovando, 2018). Al analiza los collages realizados por Meier, también encontramos el uso de un sistema de retícula en esta tres variables y que se logran evidenciar en sus obras artística

En el collage de la Figura 1 se evidencia una Huperposión de retículas ortogonales. La com superposión de reticulas ortogonales. La conposicion general parte de un chadrado que se va dividiendo en otros cuadrados con menores y que en cierto punto se genera un pequeño giro con una linea curva que al ojo del observador termina siendo un punto focal y de rompimiento importante. Para el caso de la Figura 2, Meier decide yuxtaposicionar dos reticulas una encima de la otra. de las cuales una se alinea con el borde de la base utilizada y a la otra le da un giro con respecto de la otra de 5 grados.
Figura. 1. Nota della Biancheria (Meier, 1992)

Fuente: Tomada de Collage and
Architecture de Jennifer A. E. Shields
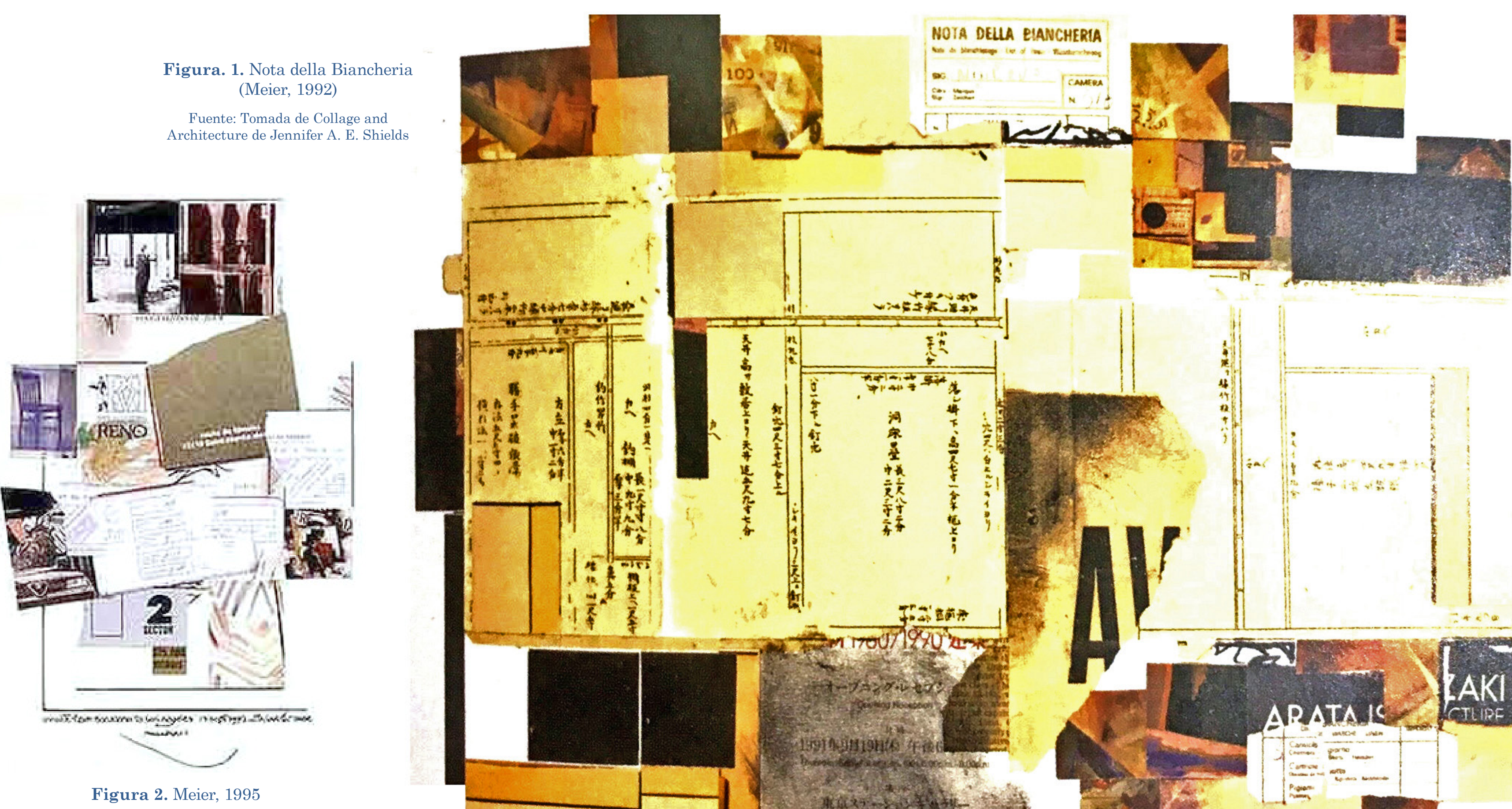

Fuente: Tomado d

richard-meier-collages/ 


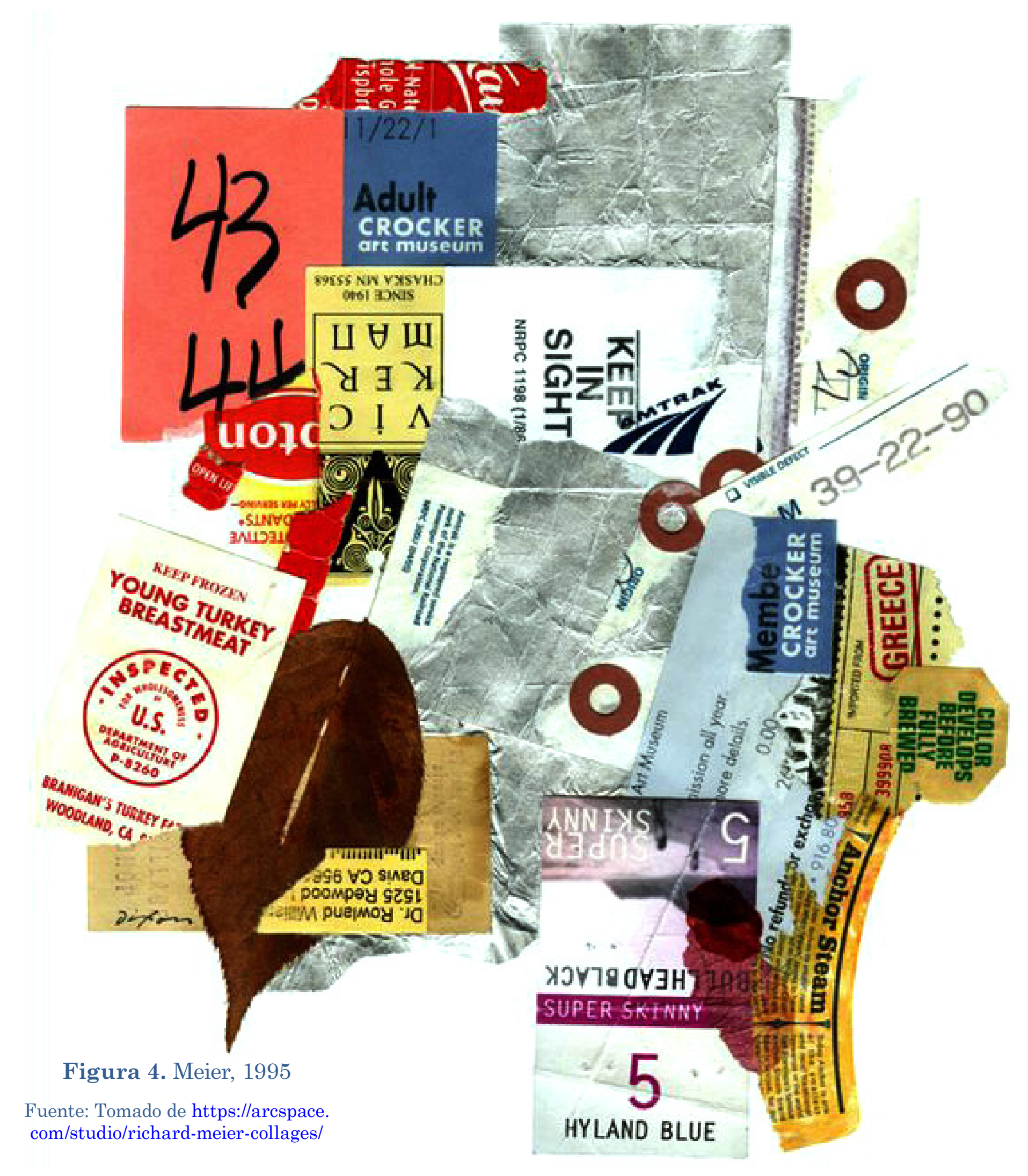

Algo muy parecido ocurre en la Figura 4, dontes elementos referenciales como lo son boleto rectangular de metro y el papel de color rojizo con los números 43 y 44 para organizar el conjunto de la composición. Con base en estos tres elementos referentes, Meier traza dos retículas superpuestas entre sí, girando una de ellas 22,5 grados respecto a la otra. Mientras que el boleto rectangular de metro crea una línea o eje transversal que atraviesa la composición logrando desviar la mirada del observador y hacer notar los tres elementos circulares y las manchas de tinta. A su vez dan pie para generar líneas curvas de ese lado del collage y que rompen con las retículas ortogonales.

En el caso de la casa Douglas, para poder generar un diseño de capas, Meier organizó el programa en zonas determinadas en sus funciones, tanto públicas como privadas y que se agrupan en dos zonas consecutivas perpendiculagrupan de entrada (Figura 5). La iluminación es de sume impotancia tara s). La ilu las disciar y las divich divison tanto espcial zona privada son en

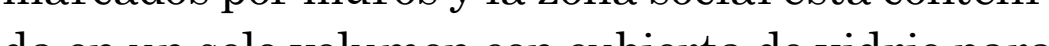
el ingreso de la luz natural (Dahabreh, 2014). 


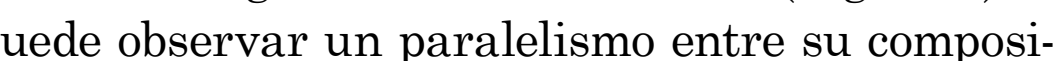
ción y la organización espacial de la casa Douglas. Se nota claramente el uso de una retícula ortogonal, pero con grandes espacios en blanco que dan la sensación del paso de la luz. Por un lado, unas cuatro imágenes pequenas enmarcadas con un espacio en blanco separada, por un elemento rectangular colocado de manera horizontal donde se aprecia el desnudo de una mujer en tres fotografías distintas y que dan la sensación de movimiento, de dos grandes imágenes de mayor peso que junto con otro espacio en blanco generan un solo marco mucho mayor. Los espacios en blanco organizan y dividen las distintas zonas de la composición del collage y se vuelven parte importante de la misma imagen.

En el caso del Museo de Arte Contemporáneo de Barcelona (Macba) el edificio se caracteriza por la yuxtaposición de formas, ubicadas sobre una retícula generada por las características del lugar (Figura 7). El uso de círculos, líneas diagonales, líneas curvas y la retícula está regulado por el uso de la geometría y los sistemas de proporción (Dahabreh, 2006). La retícula ortogonal se impone ante las demás formas que en cierto modo quedan subyugadas por la misma. Y se crean capas distintas. Estas capas visuales expresan la zonificación funcional, las divisiones de las distintas salas de exposición y los espacios de circulación y recorridos (Dahabreh, 2006). 
En la Figura 8 se logra apreciar de forma muy marcada una retícula ortogonal con un eje casi cental dado por el cambio del color rojo naranjo. Así mismo superpuesta a la refícla

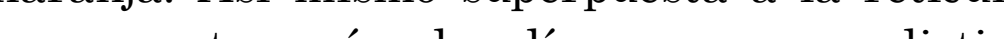
se encuentran cirintas for la rectas de la reticula pincipal que son

$$
\text { Conclusiones }
$$

A modo de conclusión se puede señalar que, al A modo de utilizar uno her ta proyectul de sus obras arquitecticas, para proyectual de lus un lanálisis de los distintos mismo arquitecto crea, se obtuvieron resultalos diagramas explicativos de sus obras arilos diagramas explicativos de sus obras arqui-

Efectivamente los conceptos de forma, estética que ha logrado Meier surge de la constante aplicación de conceptos de ortogonalidad rotación y giros axiales (Cabas, 2012). Según Cristian Ujueta (2002), Meier crea una arquitectura exquisita de alto costo y exclusiva, una arquitectura luminosa, limpia y sin monotonía (Cabas, 2012)

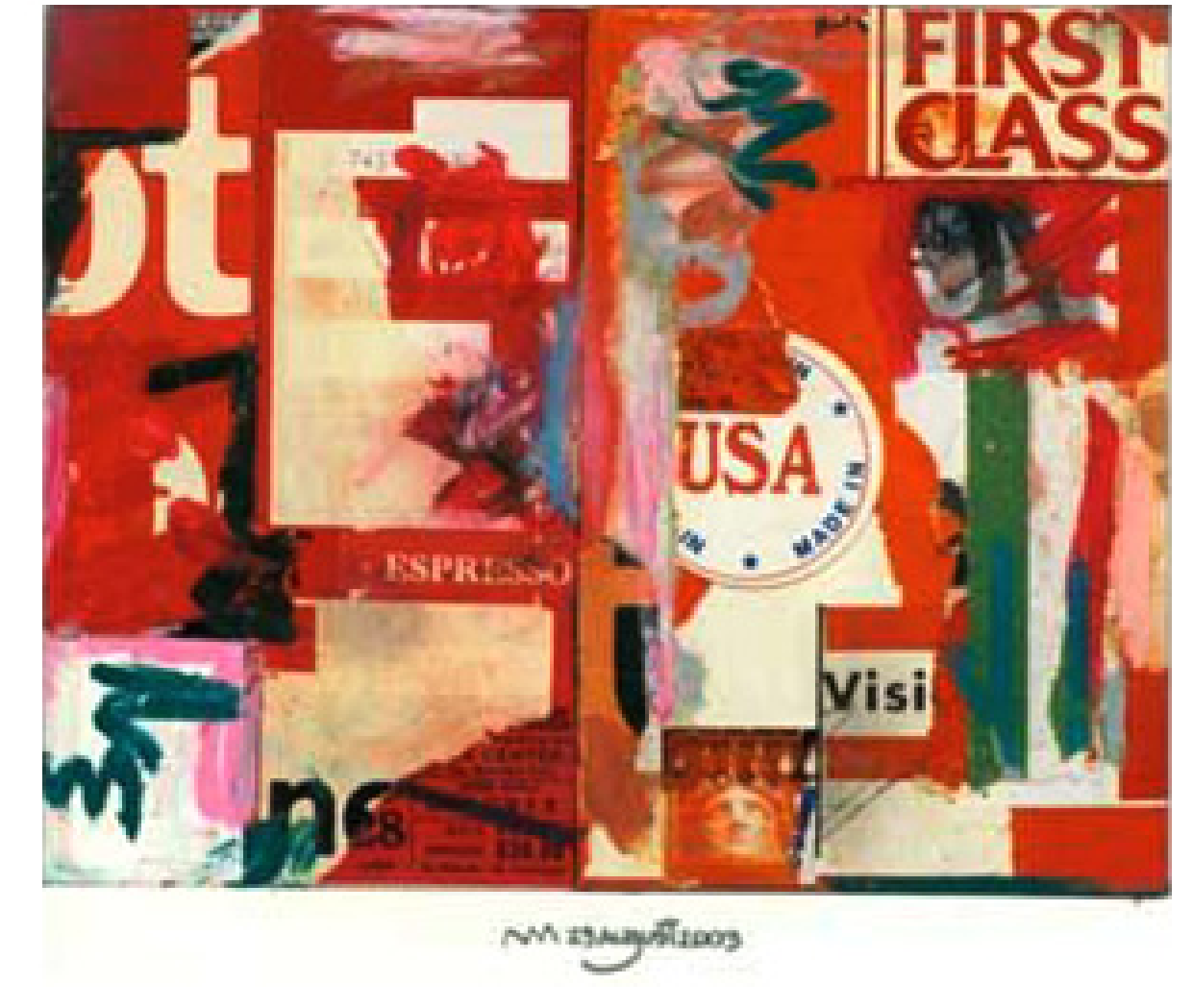

Figura 8. Meier, 1998

Fuente: Tomado de https:///oollagevolupte.wordpress.
com/2013/1/2/21/architecture-pastel
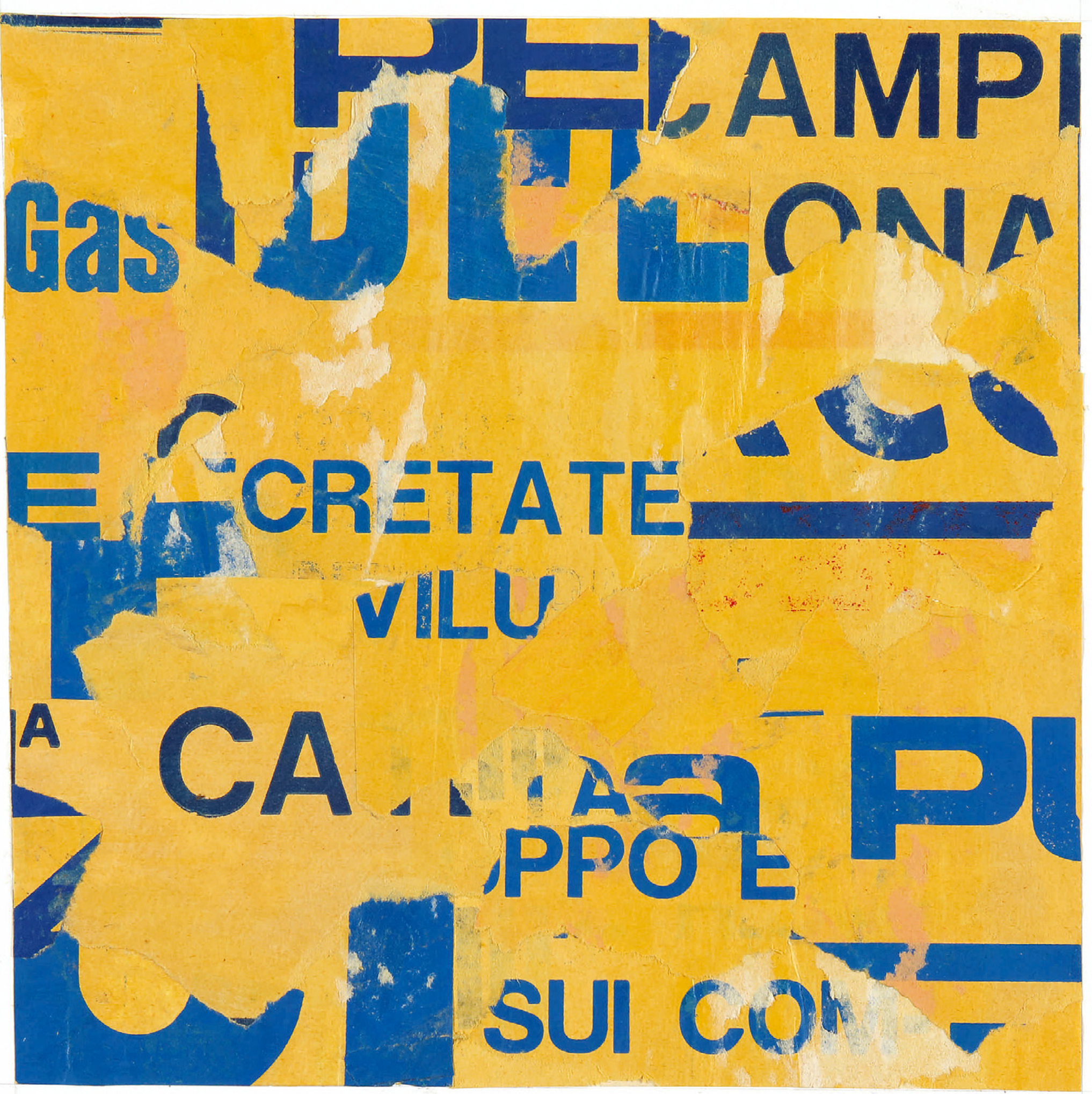

Figura 9. GAS, 1998 


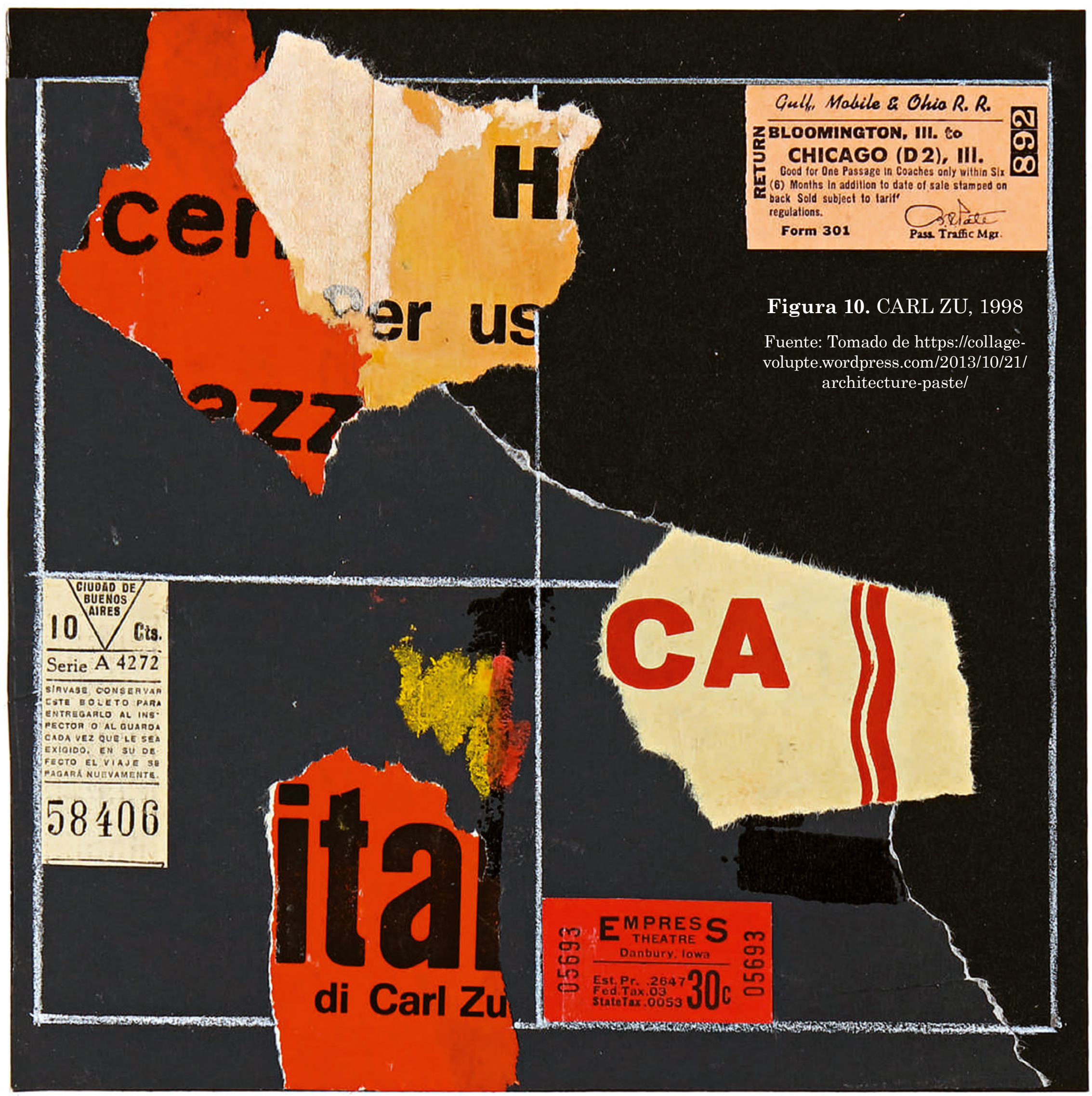


Los collages de Richard Meier demuestran la gran influencia que genera la geometría en sus actos compositivos y a pesar de ser completamente originales y hechos a veces espontáneamente se parecen mucho a su arquitectura. La técnica del collage, tiene esa gran ventaja, mediante su uso, se pueden trasladar ideas de un proyecto a otro, la arquitectura no parte de cero, parte de ideas abstractas que se arman como rompecabezas (Bianchi y Perez, 2008).

$\mathrm{Al}$ igual que a un esquema o dibujo se le puede agregar cualquier otra recurso gráfico o visual, a los collages también se le podría añadir otro recurso que le dé más características a su significado, convirtiéndolos en elementos muchos más comunicativos y arquitectónicos y hasta como objetos publicitarios (Salgado et al., 2017). Y es que el collage, no se entiende como una obra de arte en sí mismo, sino como un elemento visual de fácil explicación o interpretación (Sarasola, 2013), y para montarlo o crearlo se requiere un arte muy organizado, no un arte caprichoso (De Prada, 2004). El proceso de hacer collages Richard Meier, es así, es un proceso donde el orden de la composición esta dado por normas, proporciones y retículas al igual que su arquitectura.

Generalmente, el proceso creativo empieza con las manos, que son las que permiten crear un objeto de diseño, desarrollando las ideas y conceptos en esquemas, diagramas, dibujos, maquetas y hasta collages. Y de cierta manera llegan a representar a quien los realiza (Alba, 2013). Los collages de Richard Meier son claro ejemplo de esto. Representan su orden, sus giros, yuxtaposiciones y hasta el manejo de la luz que caracteriza su arquitectura.

El análisis anterior de los collages de Meier lleva a una serie de conclusiones: la imagen final del collage depende de la interacción entre los materiales y una organización formal, sin que ninguna de las dos sea de mayor peso que la otra. Así como los conceptos espaciales abstractos, como la rotación, se materializan en sus edificios (Dahabreh, 2014), en sus collages también se ven materializados. Y podría decirse que sus collages también están regulados por sistemas dimensionales y proporcionales. Las obras de arte que Meier obtiene al hacer collages, son producto de su imaginación y generan un proceso que permite percibir sensaciones visuales en esas imágenes. Este proceso se nutre por medio de recuerdos, experiencias, vivencias y momentos. Tal cual como lo expresa Raposo (2014), "Las imágenes son los esquemas de organización y configuración de los contenidos de la imaginación" (p. 1). En este caso los collages de Meier podrían darnos una idea que como está organizada la imaginación y el pensamiento de este arquitecto. 
A lo largo de la carrera de Richard Meier, su arquitectura y sus collages se han ido transformando gradualmente, y en cierto punto sus trabajos arquitectónicos llegan a parecerse a sus trabajos artísticos o a sus collages, aunque lo que sí es completamente cierto es que el hacer collages lo entrena, inspira y motiva a hacer buena arquitectura (Shields, 2014).

\section{REFERENCIAS}

Alba, M. I. (2013). Manos que piensan. reflexiones acerca del proceso creativo del proyecto de arquitectura. Ega, (22), 196-203. https://doi.org/10.4995/ega.2013.1694

Arnheim, R. (2001). La forma visual de la arquitectura. Barcelona: Gustavo Gili.

Aschner, J. P. (2009). ¿Cómo concebir un proyecto arquitectonico? Dearq, 5(1), 30-41.

Bianchi, S. y Pérez, L. (2008). Guillermo Jullian. La paleta del arquitecto. Arq, (70), 74-81. http://dx.doi.org/10.4067/S071769962008000300016

Bielefed, B. (2013). Basics Architectural Design. Basel: Birkhauser.

Bonsiepe, G. (2006). Design and Democracy. Design Issues, 22(2), 27-35.

Cabas, M. (2017). La Maqueta: Herramienta Esencial. Ega, 22(29), 248-255. https://doi. org/10.4995/ega.2017.7354

Cabas, M. (2012). Richard Meier: Organización racional,estructuralismo espacialy luz. Arte \& diseño, 10(2), 5-11. Disponible en https:// studylib.es/doc/5568985/richard-meier-organización-racional--estructuralismoesp...
Cambridge University Press. (noviembre 15, 2018). Cambrigde Dictionary. [Online]. Available from https://dictionary.cambridge.org/es/diccionario/ingles/collage

Castellanos, A. y Rodriguez, F. (2016). La gestión proyectual del diseño: aportes desde la comunicación, el pensamiento visual y el pensamiento de diseño. Kepes, 13(14), 141-176. https://doi.org/10.17151/ kepes.2016.13.14.7

Dahabreh, S. (2014). The Hidden Geometry of the Douglas House. Research Journal of Applied Sciences, Engineering and Technology, (12), 2483-2490. https://doi. org/10.19026/rjaset.7.556

Dahabreh, S. (2006). The formulation of design: the case of the islip courthouse by richard meier. Georgia: Institute of Technology.

De Molina, S. (2014). Collage y Arquitectura: La Forma intrusa en la construcción del proyecto moderno. Sevilla: Recolectores urbanos.

De Piccoli, G. (2015). La función simbólica en la arquitectura: arquetipos. Modulo Arquitectura CUC, 14(1), 119-134. http://dx.doi. org/10.17981/moducuc.14.1.2015.7

Der Mass, S. (2011). El diagrama en la arquitectura. Dearq, (8), 32-43.

Layuno, A. (2016). Concepto y representación espacial en la arquitectura expositiva del movimiento moderno. Reflexiones sobre la retícula, el vacío y la transparencia. $E G A$, 21(28), 156-167. https://doi.org/10.4995/ ega.2016.6325 
Meier, R. y Logan, R. (octubre 3, 2016). Las Calles medievales inspiraron la organización lineal del Macba. [Online]. Disponible en https://docplayer.es/13091682-Las-callesinspiraron-la-organizacion-medievaleslineal-del-macba.html

Meier, R., Williams, H., Lacy, B. \& Roundtree, S. (1991). The Getty Center. Design Process. Los Angeles: The J. Paul Getty Trust.

Moxey, K. (2009). Los estudios visuales y el giro icónico. Estudios Visuales, (6), 8-27.

Nesbitt, L. (1990). Richard Meier Collages. New York: Academy Editions and St Martin's Press.

Ovando, F. (2018). La Retícula en el proyecto Arquitectónico Richard Meier. Ega, 23(33), 169-177. https://doi.org/10.4995/ ega.2018.7737

Prada, M. (2004). El sentido del montaje y las técnicas del collage. Cuadernos de Notas, (10), 101-114. Disponible en http://polired. upm.es/index.php/cuadernodenotas/article/ view/689
Raposo, J. (2014). Dibujar, procesar, comunicar: el proyectar arquitectónico como origen de un proceso grafico-plástico. Implicaciones docentes. Ega, (21), 92-105. https:// doi.org/10.4995/ega.2014.3091

Salgado, M., Raposo, J. \& Butragueño, B. (2017). Retórica gráfica. El dibujo del arquitecto como herramienta de comunicación crítica. Arte, individuo y sociedad, 29(3), 587-602. http://dx.doi.org/10.5209/ ARIS.56053

Sarasola, F. (2013). Un collage de jorge otei$\mathrm{za}$, croquis de su instituto internacional de investigaciones estéticas comparadas. San juan de luz, 1963. EGA, (21), 236-245. http://dx.doi.org/10.4995/ega.2013.1537

Shields, J. A. (2014). Collage and architecture. New York: Taylor \& Francis.

Spaeth, D. (1985). Mies Van Der Rohe. New York: Rizzoli.

Ujueta, C. (2002). La Arquitectura en la cultura occidental. Barranquilla: Ediciones Uniautonoma.

Vallespin, A., Cervero, N. \& Cabodevila, I. (2017). Los collages de la casa resor de mies van der rohe. Ega, 140-149. https:// doi.org/10.4995/ega.2017.7392 
Articulo producto de la investigación titulada "El concepto del espacio arquitectónico contemporáneo. Acercamiento teórico a los conceptos de Richard Meier; Rem Koolhaas y Zaha Hadid" dirigido por el arquitecto Mauricio Cabas

Alberto Gutiérrez Lacombe es Arquitecto y docente catedrático de la Universidad de la Costa CUC (Colombia). 